\title{
Temporal integration in second-order conditioning and sensory preconditioning
}

\author{
ROBERT C. BARNET \\ Dalhousie University, Halifax, Nova Scotia, Canada \\ and \\ ROBERT P. COLE and RALPH R. MILLER \\ State University of New York, Binghamton, New York
}

\begin{abstract}
Lick suppression experiments with rats revealed that the magnitude of both second-order conditioning (Experiment 1) and sensory preconditioning (Experiment 2) was superior when that conditioning was based on backward (US $\rightarrow$ CS) relative to forward (CS $\rightarrow$ US) first-order pairings of a CS and US. The superiority of backward relative to forward first-order conditioning on suppression to the higher order cues can be understood by assuming that the magnitude of higher order conditioning was determined by a memory representation of the higher order cues that provided information about the expected temporal location of the US. The results suggest that temporal information such as order between paired CSs and USs was encoded, preserved, and integrated with memory for the higher order stimuli. The relevance of these findings to memory integration in Pavlovian learning, the temporal coding hypothesis (Barnet, Arnold, \& Miller, 1991; Matzel, Held, \& Miller, 1988), backward excitatory conditioning, and the associative structure that underlies second-order Pavlovian fear conditioning are discussed.
\end{abstract}

The second-order conditioning (SOC) procedure seems well suited for the investigation of memory integration. In Phase 1 of the SOC procedure, a conditioned stimulus (CS) S1 is paired with an unconditioned stimulus (US; $\mathrm{S} 1 \rightarrow$ US). During Phase 2, a novel cue S2 is paired with the preconditioned $\mathrm{S} 1(\mathrm{~S} 2 \rightarrow \mathrm{S} 1)$, after which behavioral control by $\mathrm{S} 2$ is assessed. One important question has been what associative structure underlies responding to the second-order cue, S2 (e.g., Barnet, Arnold, \& Miller, 1991; Rizley \& Rescorla, 1972). This question is directly relevant to the issue of memory integration in elementary learning, because the question of associative structure is essentially one of whether information (or responses) from one phase of training (e.g., the reinforced phase, Phase 1 of SOC) can be integrated with information from a subsequent and different phase of training (e.g., the nonreinforced phase, Phase 2 of SOC). We use the SOC and related procedures in the present work to study the integration of temporal information in animal memory. This particular focus of research was encouraged by the observation of some researchers that the study of memory integration has been neglected by students of animal behavior (e.g., Medin \& Dewey, 1986), in addition to our own develop-

Support for this research was provided by National Institute of Mental Health Grant 33881. R.C.B. was supported by the Natural Sciences and Engineering Research Council of Canada, and Killam postgraduate scholarships. We thank Christine Kerr and Lee Mattes for assistance in data collection, and Helena Matute for comments on an earlier version of the manuscript. Requests for reprints may be addressed to $\mathrm{R}$. $\mathrm{R}$. Miller, SUNY-Binghamton, Binghamton, NY 13902-6000 (e-mail: rmiller@binghamton.edu). ing interests in the mechanisms of timing in animal memory (e.g., Barnet et al., 1991; Miller \& Barnet, 1993).

One manner in which the integration of memory for temporal events can be studied is to assess the effect of manipulating temporal variables in the SOC procedure. Temporal variables can be manipulated in the SOC procedure, for example, by varying the order of associates in either Phase 1 or Phase 2 of training. In the present experiments, the temporal order of the first-order stimulus, $\mathrm{S}$, and the US was varied, and the effect of that variation on responding to the second-order stimulus, $\mathrm{S} 2$, was assessed in both SOC and sensory preconditioning (SPC) designs.

The SPC (Brogden, 1939) procedure is similar to that of SOC, except for the order of the training phases. In $\mathrm{SPC}$, training with $\mathrm{S} 2$ and $\mathrm{S} 1(\mathrm{~S} 2 \rightarrow \mathrm{S} 1$, Phase 1) precedes reinforced first-order training with $\mathrm{S} 1$ ( $\mathrm{S} 1 \rightarrow \mathrm{US}$, Phase 2). In work that has manipulated order of associates in this kind of two-phase conditioning experiment, the effect of switching the order of paired associates has generally been detrimental to responding to the higher order cue. Brown and King (1969), for example, switched the temporal arrangement of CSs in SPC so that initial Phase 1 training took the form $\mathrm{S} 1 \rightarrow \mathrm{S} 2$ instead of the more common S2 $\rightarrow$ S1. Poor responding to S2 was observed; that is, SPC did not emerge. Related evidence provided an early general consensus that switching the order of $\mathrm{S} 2 \rightarrow \mathrm{S} 1$ associates in SPC is not favorable for conditioning to S2 (Coppock, 1958; Silver \& Meyer, 1954; Tait, Marquis, Williams, Weinstein, \& Suboski, 1969).

There has, however, been at least one demonstration of effective conditioning using the $\mathrm{S} 1 \rightarrow \mathrm{S} 2$ procedure of $\mathrm{SOC}$ in flavor aversion learning by rats (Mowrer, Krug, 
\& Klein, 1988). More recently, Cole, Barnet, and Miller (1995) observed good excitatory conditioning to $\mathrm{S} 2$ in a conditioned suppression experiment despite the use of an $\mathrm{S} 1 \rightarrow \mathrm{S} 2$ procedure in both SOC and SPC designs. In Cole et al.'s experiments, conditioning to $S 2$ was robust when there was a short $(5-\mathrm{sec})$ gap between $\mathrm{S} 1$ and the US during reinforced training with $S 1$, but not when there was no gap ( 0 -sec delay) between $\mathrm{S} 1$ and the US during reinforced training. There are two reasons why this finding is potentially important. First, inserting a gap between S1 and the US is generally recognized to weaken, not strengthen, conditioned excitatory behavior (Ellison, 1964; Kimble, 1947; Pavlov, 1927). Yet in the Cole et al. report, insertion of a gap between S1 and the US actually enhanced excitatory conditioning (to S2). This finding indicates that the temporal arrangement of S1 and US that is optimal for excitatory conditioning to the higher order S2 cue may not be the optimal arrangement for conditioning to $S 1$ itself. Second, conditioning to S2 occurred despite some reports claiming a resolute failure to obtain SPC when $\mathrm{S} 1 \rightarrow \mathrm{S} 2$ pairings were used (e.g., Brown \& King, 1969). By manipulating the temporal relationship between S1 and the US, Cole et al. observed SPC (and also SOC) under conditions in which SPC might not otherwise have been expected (i.e., using $\mathrm{S} 1 \rightarrow \mathrm{S} 2$ pairings). Thus, the detrimental effect of $\mathrm{S} 1 \rightarrow \mathrm{S} 2$ pairings was overcome by manipulation of the S1-US temporal relationship. Both of these points are relevant to the present work, because they suggest that the outcome of SOC and SPC experiments is strongly influenced by the temporal arrangement of S1 and the US during the reinforced phase.

We investigated this issue further in the present work by varying the temporal arrangement of S1 and the US in both SOC and SPC designs. The possibility that rats encode and integrate temporal information across separate phases of training was evaluated in these experiments by comparing of the magnitude of SOC (Experiment 1) or SPC (Experiment 2) that emerged after backward (US $\rightarrow \mathrm{S} 1$ ) versus forward (S1 $\rightarrow$ US) first-order training. In one related (SPC) report by Matzel, Held, and Miller (1988, Experiment 2), different groups of rats were exposed to either backward (US $\rightarrow \mathrm{S} 1$ ) or forward (S1 $\rightarrow \mathrm{US}$ ) first-order conditioning with S1 after forward preconditioning with $\mathrm{S} 2$ ( $\mathrm{S} 2 \rightarrow \mathrm{S} 1)$. As we did in the present experiments, Matzel et al. compared the magnitude of responding to $\mathrm{S} 2$ after backward (US $\rightarrow \mathrm{S} 1$ ) or forward (S1 $\rightarrow$ US) first-order conditioning with S1 and the US. Those authors observed no difference in the response potential of S2 depending on whether the first-order cue had been forward or backward paired with the US. However, the provision of backward or forward first-order pairings to different groups in Matzel et al. may have had different effects on the associative value of the context, thereby introducing a confound into their design. Specifically, the USs of a backward conditioning arrangement are unsignaled (US $\rightarrow \mathrm{S} 1$ ), whereas those of a forward conditioning arrangement are signaled ( $\mathrm{S} I \rightarrow U S$ ). It has been suggested that signaled and unsignaled USs have different effects on the associative value of the context (Rescorla, 1984). Therefore, one problem with the between-subjects design of Matzel et al. is that it potentially confounds the backward versus forward first-order conditioning manipulation with the associative value of the conditioning context. In the present experiments, we attempted to overcome this and other potential difficulties.

\section{EXPERIMENT 1}

The goal of Experiment 1 was to determine whether the magnitude of SOC differs depending on whether the first-order cue had been forward (S1 $\rightarrow$ US) or backward $(\mathrm{US} \rightarrow \mathrm{S} 1$ ) paired with the US. Table 1 shows the design. At least three important benefits of the present design may be identified. First, the design uses a within-subjects training procedure for forward and backward first-order conditioning (see Table 1, Phase 1). Use of this procedure allows comparison of responding to second-order cues that is not confounded by potential differences in the associative value of the context existing at the time secondorder training occurs, or at the time of testing. Second, second-order training is conducted in a context different from that used for (reinforced) first-order training, specifically, a context in which no USs or CSs have been presented prior to the start of second-order training (see Table 1, Phase 2 for experimental [SOC.exp] and control [SOC.con] groups). This protocol essentially eliminates the contribution of responding to the second-order cue that could arise from pairing the second-order cue with an excitatory context (Marlin, 1983). To the extent that contextUS and S1-US associations both contribute to secondorder conditioning (cf. Grau \& Rescorla, 1984), conducting second-order training in a neutral context should allow us better to evaluate the associative structure that underlies control by the second-order CS (i.e., by unconfounding the contribution of an excitatory context present at the time of second-order training). Third, the design conducts the test for second-order conditioning in a context in which no USs have ever been presented. By doing so, we attempt to eliminate the possibility that di-

Table 1

Experiment 1 (SOC): Design Summary

\begin{tabular}{lccc} 
& \multicolumn{3}{c}{ Treatment } \\
\cline { 2 - 3 } Group & Phase 1 (Context Train) & Phase 2 (Context Test) & \\
\hline SOC.exp & $\mathrm{S} 1 \rightarrow \mathrm{US} / \mathrm{US} \rightarrow \mathrm{S} 2$ & $\mathrm{~S} 3 \rightarrow \mathrm{S} 1 / \mathrm{S} 4 \rightarrow \mathrm{S} 2$ & (Test S3 and S4) \\
SOC.con & $\mathrm{S} 1 \rightarrow \mathrm{US} / \mathrm{US} \rightarrow \mathrm{S} 2$ & $\mathrm{~S} 1 / \mathrm{S} 2 / \mathrm{S} 3 / \mathrm{S} 4$ & (Test S3 and S4) \\
First-order & $\mathrm{S} 1 \rightarrow \mathrm{US} / \mathrm{US} \rightarrow \mathrm{S} 2$ & (Test S1 and S2) & \\
\hline Note- “ $\rightarrow$ " means "followed by"; "/" means "unpaired with." &
\end{tabular}


rect control by context-US associations will summate with control by the (second-order) test CS (Miller, Grahame, \& Hallam, 1990). These various aspects of design were intended to provide relatively rigorous control over extraneous and potentially confounding variables that (1) are typically not brought into consideration by most studies of second-order and sensory preconditioning, and (2) might become especially important in SOC and SPC experiments in which the order of CS and US associates is manipulated.

One prediction for the course of SOC emerges from a general consideration of the excitatory status of the firstorder CS. If the first-order CS is strongly excitatory, that excitation might be expected to transfer to the secondorder CS during the second-order conditioning phase. Conversely, if the first-order CS is only weakly excitatory, that excitation might be expected to transfer to the second-order cue. In one report consistent with this expectation, Kehoe, Feyer, and Moses (1981, Experiment 3), using the rabbit's nictitating membrane response as a measure of conditioning, also investigated the effect of varying the temporal relationship between a first-order S1 and the US on excitatory SOC. However, those authors used the standard procedure of forward Sl $\rightarrow$ US (Phase 1) followed by $\mathrm{S} 3 \rightarrow \mathrm{S} 1$ (Phase 2) and manipulated the interstimulus interval between $\mathrm{S} l$ and the US in Phase 1 (the second-order cue is now referred to as " $S 3$," simply to preserve consistency with the nomenclature of Table 1). The relevant observation was that the response potential of S3 was predictable from and parallel to that of S1 under different variations of the S1-US interstimulus interval. Stated differently, the excitatory status of the first-order cue in their report was directly related to the resulting character of SOC. An according prediction for outcomes of the present experiment is that the excitatory status of the second-order stimulus will track that of the first-order cue with which it was paired. Thus, in the scheme of Table 1, the level of excitatory conditioning to S3 should track that of S1, and the level of excitatory conditioning to S4 should track that of S2.

A related prediction for SOC arises from our use of backward US $\rightarrow \mathrm{S} 2$ training as a first-order conditioning treatment. This treatment is capable of establishing the backward CS as an inhibitor (Moscovitch \& LoLordo, 1968; Siegel \& Domjan, 1971), and Rescorla (1976) has demonstrated second-order conditioned inhibition by pairing a second-order CS with an established inhibitor. If the backward US $\rightarrow$ S2 pairings of the present experiment support the acquisition of inhibition to $\mathrm{S} 2$, secondorder training with S4 (S4 $\rightarrow \mathrm{S} 2$, see Table 1) could potentially transform $\mathrm{S} 4$ into a conditioned inhibitor. To the extent that $\mathrm{S} 4$ acquires inhibitory value, robust excitatory control by $\mathrm{S} 4$ might not be expected. However, given that the number of backward US $\rightarrow$ CS pairings has been implicated in the acquisition of inhibition to a backward CS (Heth, 1976), it is possible that the number of US $\rightarrow$ S2 pairings in the present experiment was insufficient for the establishment of S2 as a strong inhibitor. Nevertheless, considering S2 even as a weak inhibitor could lead to the prediction that excitatory $\mathrm{SOC}$ to $\mathrm{S} 4$ will be inferior to that of $\mathrm{S} 3$.

A different pattern of results is anticipated by our view of associative learning that we have called the temporal coding hypothesis (Barnet et al., 1991; Matzel et al., 1988). As a working hypothesis, this view assumes that temporal contiguity between paired associates such as CSs and USs is sufficient for associative learning but not for the expression of that learning. In order for associative learning to be expressed in excitatory behavior during the test, there must be a predictive expectancy between the test stimulus and the US. The view further assumes that the temporal relationship that obtains among paired associates during training is encoded as part of the association. In other words, Pavlovian associations do more than link event representations in memory; they also encode information about the temporal relationship between the associates that prevail during training (see Desmond \& Moore, 1988; Schreurs \& Westbrook, 1982, for related views). The basis for predictions of the temporal coding hypothesis, given the present design, is summarized in Figure 1.

In this view, temporal information arising from firstorder $\mathrm{S} 1 \rightarrow \mathrm{US}$ and US $\rightarrow \mathrm{S} 2$ conditioning may be encoded, preserved, and integrated with memory for the secondorder cues. The resulting associative structure of this tem-

HYPOTHETICAL MEMORY REPRESENTATIONS

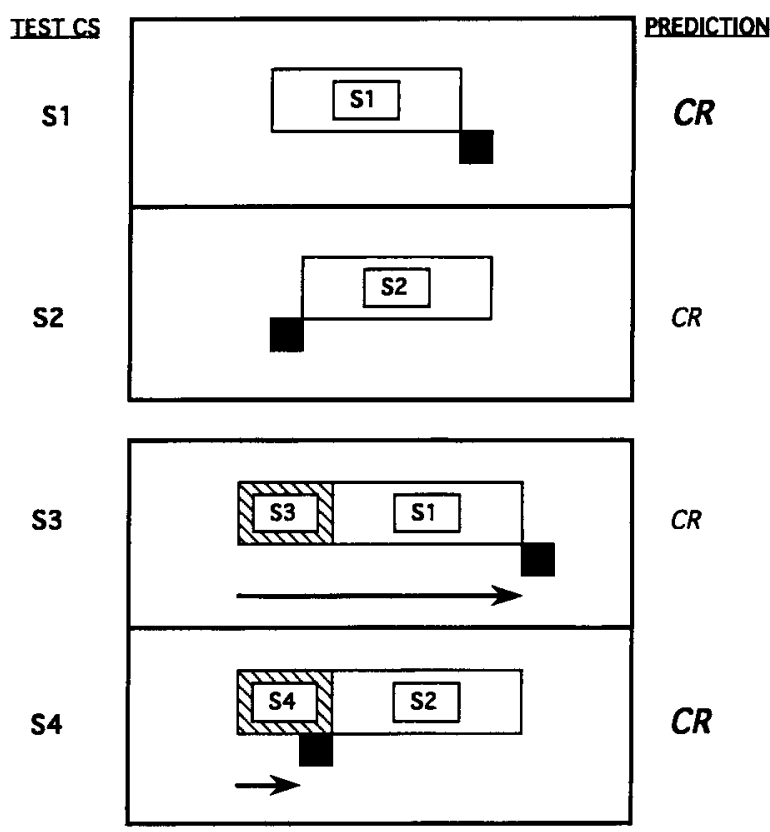

Figure 1. Possible representational structures after forward or backward first-order conditioning (top two panels) and after higher order conditioning based on either forward or backward first-order conditioning (bottom two panels). Open and hatched boxes reflect memory representations for particular CSs $(\mathbf{S 1}, \mathbf{S 2}$, S3, or S4). The solid black squares represent memory for the US, and the arrow length in the bottom two panels reflects the temporal character of expectancy for the US upon onset of the test CS. 
poral integration is similar to Honig's (1981) notion of a temporal map, which is conceptualized as a memorial representation that incorporates temporal attributes from different learning experiences. Figure 1 illustrates one possibility for the nature of information that such a temporal map could provide, and how differences in that temporal information might serve as a basis for generating predictions in the present experiment.

In Figure 1, open and hatched boxes illustrate memory representations for particular CSs, and the small black squares illustrate memory for the US. The top portion of Figure 1 shows possible memorial representations resulting from forward first-order conditioning with S1 and backward first-order conditioning with S2. It is presumed that, after conditioning has occurred, these are the memory representations that could become activated upon presentation of S1 and S2, respectively. In these representations, memory for the temporal location of the US is consistent with that which occurred during reinforced training (i.e., the black box illustrating the US occurs after S1 but occurs before S2). This depiction reflects the assumption of the temporal coding hypothesis that associations between a CS and US encodes the temporal relationship that prevailed during training. The bottom portion of Figure 1 shows possible memory representations activated by test presentations of S3 and S4 after SOC has occurred. It is here that the notion of temporal integration is illustrated. Memory for $\mathrm{S} 3$ precedes that of $\mathrm{S1}$, and memory for $\mathrm{S} 4$ precedes that of $\mathrm{S} 2$, because these cues have been forward paired during secondorder conditioning ( $\mathrm{S} 3 \rightarrow \mathrm{S} 1 / \mathrm{S} 4 \rightarrow \mathrm{S} 2$; see Table 1). Note that the temporal relationship between $\mathrm{S} 1$ and the US and between S2 and the US has been preserved in these integrated memory representations. The preservation of that order has important implications for the expected temporal location of the US during the test with the second-order cues. Specifically, the expected temporal location of the US is different for $\mathrm{S} 3$ and $\mathrm{S} 4$. This difference is illustrated by the length of the arrows in Figure 1. Upon onset of S4 during the test (after SOC has occurred), animals might expect the US to be delivered a short time thereafter (i.e., within $5 \mathrm{sec}$, because $\$ 4$ was $5 \mathrm{sec}$ during training) and consequently, $\mathrm{S} 4$ could acquire strong excitatory control. Likewise, animals might expect the US to be presented after onset of $S 3$, but at a considerably longer delay (e.g., within $15 \mathrm{sec} ; 5 \mathrm{sec}$ for $\mathrm{S} 3$ and $10 \mathrm{sec}$ for $\mathrm{SI}$ as during training), and excitatory control by S3 might be accordingly weaker. ${ }^{1}$ Thus, two accounts that potentially make different predictions may be identified. In what may be referred to as the "associative transfer" hypothesis, the associative character of the first-order cues transfers to the second-order stimulus. In the "temporal encoding" or "temporal integration" hypothesis, order information, encoded in associations to the first-order cues, becomes integrated with memory of the second-order stimulus. The response potential of the second-order cue is then determined by the expected temporal location of the US relative to presentation of the second-order stimulus during testing.

\section{Method}

\section{Subjects}

The subjects were 30 male and 30 female naive Sprague-Dawleydescended rats. Body weight ranges were $320-485 \mathrm{~g}$ for males and 225--305 g for females. Each animal was assigned to one of three groups counterbalanced for sex. The animals were individually housed in standard hanging, stainless steel, wire mesh cages in a vivarium maintained on a 16:8-h light:dark cycle. Experimental manipulations occurred near the midpoint of the 16-h light cycle. The animals were allowed free access to Purina Laboratory Chow in their home cages. Starting 1 week prior to initiation of the study, all animals were progressively deprived of water. By Day 1 of the study, access to water in the home cage was limited to $10 \mathrm{~min}$ per day, which was thereafter provided 18-22 h prior to any treatment scheduled for the following day. All subjects were handled three times per week for $30 \mathrm{sec}$ from weaning until the initiation of the study.

\section{Apparatus}

Two types of experimental chambers were used. Chamber 1 was rectangular in shape and measured $22.75 \times 8.25 \times 13.0 \mathrm{~cm}$. The walls and ceiling were constructed of clear Plexiglas. The floor was constructed of stainless steel rods, $0.48 \mathrm{~cm}$ in diameter. The rods were spaced $1.5 \mathrm{~cm}$ apart, center to center. They were connected through NE-2 neon bulbs, which allowed constant-current footshock to be delivered by means of a high-voltage ac circuit in series with a 1.0-M $\Omega$ resistor. Each of six copies of Chamber 1 was contained in a sound- and light-attenuating environmental isolation chest. Chamber 1 was illuminated by a $2-W$ (nominal at $120 \mathrm{~V} \mathrm{ac}$ ) houselight driven at $56 \mathrm{~V}$ ac. The houselight was mounted on an inside wall of the environmental isolation chest approximately $30 \mathrm{~cm}$ from the center of the experimental chamber.

Chamber 2 was a $25.5-\mathrm{cm}$-long box in the shape of a truncated V. This chamber was $28 \mathrm{~cm}$ high and $21 \mathrm{~cm}$ wide at the top, narrowing to $5.25 \mathrm{~cm}$ wide at the bottom. The ceiling was constructed of clear Plexiglas, and the narrow end walls were constructed of black Plexiglas. The floor and $25.5-\mathrm{cm}$-long sidewalls were constructed of sheet metal. The floor consisted of two $25.5-\mathrm{cm}$-long parallel metal plates, each $2 \mathrm{~cm}$ wide with a $1.25-\mathrm{cm}$ gap between them. A constant-current footshock could be delivered through the metal walls and floor of the chamber. Each of six copies of Chamber 2 was contained in a light- and sound-attenuating environmental isolation chest. Chamber 2 was illuminated by a $7.5-\mathrm{W}$ (nominal at $120 \mathrm{~V} \mathrm{ac}$ ) houselight driven at $56 \mathrm{~V}$ ac. The houselight was mounted on an inside wall of the environmental isolation chest, approximately $30 \mathrm{~cm}$ from the center of the experimental chamber. Light entered the animal chamber primarily by reflection from the roof of the environmental chest. These light intensities roughly matched those in Chamber 1, owing to differences in the opaqueness of the chamber walls.

Each of Chambers 1 and 2 could be equipped with a water-filled lick tube. When inserted, the lick tube protruded $1 \mathrm{~cm}$ into a cylindrical drinking recess that was set into one of the narrow Plexiglas walls of the chamber (axis perpendicular to the wall). The recess was left-right centered on the chamber wall, and was centered $3.5 \mathrm{~cm}$ above the chamber floor. Each recess was $5.0 \mathrm{~cm}$ deep and $4.5 \mathrm{~cm}$ in diameter. An infrared photobeam was projected $0.5 \mathrm{~cm}$ in front of the lick tube and was used to detect when subjects had their heads inserted into the drinking recess. All chambers were equipped with three $45-\Omega$ speakers and a buzzer mounted on the interior back side of each environmental isolation chest. The speakers could deliver a complex tone $(3000$ and $3200 \mathrm{~Hz}$ ), a white noise, or a click stimulus $(6 / \mathrm{sec})$, each $8 \mathrm{~dB}(\mathrm{C})$ SPL above the background 
noise of $74 \mathrm{~dB}(\mathrm{C})$. The buzzer could deliver a buzz stimulus that was also $8 \mathrm{~dB}(\mathrm{C})$ SPL above the background noise of $74 \mathrm{~dB}(\mathrm{C}$; Piezo mini-buzzer, characteristic mean frequency, $400 \mathrm{~Hz}$ ).

\section{Procedure}

Central aspects of the design are summarized in Table 1. During Phase 1, three groups of subjects received identical first-order conditioning with two CSs, S1 and S2. S1 was forward paired with the $\mathrm{US}(\mathrm{S} 1 \rightarrow \mathrm{US}$ ), and S2 was backward paired with the US (US $\rightarrow \mathrm{S} 2$ ). Animals from Group First-Order $(n=24)$ were then tested for suppression to the first-order cues S1 and S2. Groups SOC.exp ( $n=$ $24)$ and SOC.con $(n=12)$ instead received Phase 2 second-order conditioning treatment (group sizes were different at this stage of training, so that equal-sized subgroups, counterbalanced for sex, could be created during later testing). In Phase 2 of SOC, Group SOC.exp received $\mathrm{S} 3$ paired with the first-order cue that had been forward conditioned with the US $(\mathrm{S} 3 \rightarrow \mathrm{S} 1)$ and received $\mathrm{S} 4$ paired with the first-order cue that had been backward conditioned with the US (S4 $\rightarrow$ S2). Group SOC.con received unpaired exposures to S1, S2, S3, and S4 stimuli. Groups SOC.exp and SOC.con were then tested for suppression to the second-order cues S3 and S4.

The present design required the use of two first-order and two second-order CSs in order to conduct second-order conditioning using a within-subjects procedure. As indicated earlier, the withinsubjects procedure affords control over a variety of associative factors that might otherwise confound the experimental design. As an added control for nonassociative factors, these cues were counterbalanced. Tone and white noise stimuli served as first-order cues, $\mathrm{S} 1$ and $\mathrm{S} 2$, and were counterbalanced in their designation as S1 or $\mathrm{S} 2$. Click and buzz stimuli served as second-order cues $\mathrm{S} 3$ and $\mathrm{S} 4$ and were similarly counterbalanced in their designation as $\mathrm{S} 3$ or $\mathrm{S} 4$. The counterbalancing scheme was nested in such a way that, for Group SOC.exp, when S3 was a click (or a buzz), the associated first-order cue, $\mathrm{S} 1$, was equally often a tone or white noise. Likewise, when S4 was a click (or a buzz), the associated first-order cue, S2, was equally often a tone or white noise.

During Phase 1 and Phase 2, S1 and S2 stimuli were $10 \mathrm{sec}$ in duration, and $\mathrm{S} 3$ and $\mathrm{S} 4$ stimuli were $5 \mathrm{sec}$ in duration. The US was a $0.5-\mathrm{sec}, 0.8-\mathrm{mA}$ footshock. For paired events in either phase (e.g., $\mathrm{S} 1$ and the US in Phase 1, or S3 and S1 in Phase 2), there was no gap between the two paired events (i.e., 0 -sec delay). Following all training, conditioning was assessed by the ability of nonreinforced presentations of test CSs to suppress ongoing drinking in waterdeprived rats.

Acclimation. Acclimation to the chambers was conducted on Days 1 and 2 . During each 60 -min session, animals were exposed to the conditioning chambers, with a water-filled lick tube available in each. For half of the animals in each group, Chamber 1 was designated as the Phase 1 first-order conditioning context (Context Train) and Chamber 2 was designated as the Phase 2 second-order conditioning and testing context (Context Test). For the other half of the animals in each group, these designations were reversed. Animals were exposed to Context Train on Day 1 and to Context Test on Day 2. No stimuli were programmed to occur on these days.

First-order conditioning (Phase 1). Following acclimation, the lick tubes were removed from all chambers. First-order conditioning was then conducted in Context Train on Day 3. All animals were exposed to four forward S1 $\rightarrow$ US pairings and four backward $\mathrm{US} \rightarrow \mathrm{S} 2$ pairings. Forward (F) and backward (B) trial types were distributed in an FBBFBFFB manner with trial onsets at 10, 14, 20, $28,32,38,46$, and 52 min into the 60 -min session.

After first-order conditioning, some animals received reacclimation and were then tested with S1 and S2 (Group First-Order), whereas other animals received SOC training (Groups SOC.exp and SOC.con) as described below.

Reacclimation. Lick tubes were reinserted into the chambers for Group First-Order, and two 60 -min reacclimation sessions were then conducted in Context Test on Days 4 and 5. These sessions served to restabilize licking prior to testing. These sessions were identical to Day 2 of acclimation.

First-order testing. Following reacclimation for Group FirstOrder, the ability of the $\mathrm{S} 1$ and $\mathrm{S} 2$ stimuli to suppress drinking was tested across 2 days in a counterbalanced fashion. On Day 6, animals were placed in Context Test and allowed to complete 5 cumulative seconds of drinking. Following the completion of 5 cumulative seconds of drinking upon placement in the chamber, a test stimulus was presented for $15 \mathrm{~min}$ (S1 for half the animals, S2 for the remainder), and times to complete an additional 5 cumulative seconds of drinking in the presence of the test stimulus were recorded. On Day 7, a similar test occurred for Group First-Order, except that the alternate test stimulus ( $\mathrm{S} 2$ or $\mathrm{S} 1$ ) was presented. In order to equate duration of exposure to the test stimuli across animals prior to the second test on Day 7, each test stimulus remained on for the fixed duration of $15 \mathrm{~min}$ on the Day 6 test for all animals. Prior to testing, 1 animal from Group First-Order became ill and was eliminated from the experiment.

Second-order conditioning (Phase 2). Groups SOC.exp and SOC.con (which had not received reacclimation and testing after first-order conditioning) received the SOC treatment on Days 4 and 5 in Context Test. For these groups, no CSs or USs had ever been presented in Context Test prior to the beginning of the second-order conditioning phase. During each 60-min session, Group SOC.exp was exposed to two $\mathrm{S} 3 \rightarrow \mathrm{S} 1$ and two $\mathrm{S} 4 \rightarrow \mathrm{S} 2$ pairings. $\mathrm{S} 3$ was paired with the first-order cue that had been forward conditioned with the US (S1), whereas S4 was paired with the first-order cue that had been backward conditioned with the US (S2). Trial types, $\mathrm{S} 3 \rightarrow \mathrm{S} 1$ and $\mathrm{S} 4 \rightarrow \mathrm{S} 2$, were distributed in an ABAB manner, respectively. The pairings were initiated $10,20,37$, and 50 min into each session. Group SOC.con received equal but separate exposures to $S 1, S 2, S 3$, and $S 4$, with CS presentations pseudorandomly distributed across the session and occurring 8 (click), 14 (white noise), 22 (tone), 28 (buzz), 36 (white noise), 42 (click), 50 (buzz), and 56 (tone) min into the session. As indicated earlier, click and buzz stimuli served as second-order stimuli, counterbalanced for $\mathrm{S} 3$ or S4 designation. Click and buzz stimuli were further counterbalanced in their designation as $\mathrm{S} 3$ or $\mathrm{S} 4$, depending on the physical stimulus that had served as S1 or S2 (when S1 was a tone, half the animals in each group received $\mathrm{S} 3$ as a click and half received $\mathrm{S} 3$ as a buzz; when $\mathrm{S} 1$ was a white noise, half similarly received S3 as a click and half received $\mathrm{S} 3$ as a buzz, etc.).

Reacclimation. Following second-order conditioning for Groups SOC.exp and SOC.con, lick tubes were reinserted for these groups and two reacclimation sessions were administered on Days 6-7 in Context Test. Animals were exposed to the chamber for 60 -min sessions, during which no stimuli were programmed to occur.

Second-order testing. The ability of S3 and S4 to suppress ongoing drinking in Context Test was then tested across 2 days (Days $8-9$ ) in a counterbalanced fashion for Groups SOC.exp and SOC.con. The tests were procedurally identical to those during the first-order CS tests, except for the test stimulus presented. Group SOC.con received similar tests with the $\mathrm{S} 3$ and $\mathrm{S} 4$ stimuli (i.e., click and buzz). Note that the S3 and S4 designations in Group SOC.con are arbitrary, because these stimuli had been explicitly unpaired with $\mathrm{S} 1$ and $\mathrm{S} 2$ during the second-order conditioning phase. Prior to statistical analysis, all suppression data were converted to log (base 10) seconds to permit the use of parametric statistics. An alpha level of .05 was adopted for tests of statistical significance.

\section{Results and Discussion}

The experiment revealed that SOC tended to be superior when the first-order cue upon which SOC was based had been backward paired with the US, relative to when the first-order cue had been forward paired with the US. 
Results from the tests with the second-order cues (S3 and S4) and the first-order cues (S1 and S2) are presented in Figure 2. Initial analyses of suppression to the secondorder cues revealed an interaction with order of testing (although the general pattern of suppression to S3 and S4 did not differ depending on order of test). Consequently, these data from Test 1 and Test 2 were analyzed and presented separately. As can be seen in Figure 2, S4 supported more conditioned suppression than did $\mathrm{S} 3$, and this pattern of suppression to the second-order cues was observed on both days of testing. Such an outcome suggests that conditioning to a second-order cue is superior when that conditioning is based on first-order backward conditioning (US $\rightarrow \mathrm{S} 2$ ) than when that conditioning is based on standard first-order forward conditioning ( $\mathrm{Sl} \rightarrow \mathrm{US}$ ).

Two one-way analyses of covariance (one for each day of testing) were conducted with pre-CS scores as the covariate, and planned comparisons were then conducted with the error term from each analysis. The Test 1 analysis revealed an overall effect of test stimulus $[F(2,32)=$ $11.91, p<.001]$. Subsequent comparisons indicated that suppression to $\mathrm{S} 3$ and $\mathrm{S} 4$ each differed from control suppression $[F \mathrm{~s}(1,32) \geq 7.96, p \mathrm{~s}<.01]$. Of central interest, suppression to $S 4$ was superior to that of $\mathrm{S} 3[F(1,32)=$ $4.50, p<.05]$. A similar Test 2 analysis also revealed an overall effect of test stimulus $[F(2,32)=14.15, p<.001]$. Planned comparisons indicated that suppression to $\mathrm{S} 4$ differed from that in the control condition $[F(1,32)=28.13$, $p<.001]$, but that suppression to $\mathrm{S} 3$ did not. As can be seen in Figure 2, suppression to $\mathrm{S} 4$ was superior to that to $\mathrm{S} 3[F(1,32)=16.60, p<.001]$. Data from the tests with the first-order cues were as expected and are summarized in the right portion of Figure 2. Suppression to the forward conditioned S1 was superior to that to the backward conditioned S2. Suppression to S1 was superior to that to S2 on each test, and an overall ANCOVA with pre-CS scores as the covariate revealed an effect of test stimulus $[F(1,22)=25.06, p<.001]$. The same overall ANCOVA also revealed an interaction with order $[F(1,22)=10.66$, $p<.01]$, and subsequent ANCOVAs conducted on data from each day separately also revealed effects of test stimulus $[F \mathrm{~s}(1,21) \geq 6.84, p \mathrm{~s} \leq .015$; Day 1 means in $\log \sec \pm S E, \mathrm{~S} 1=1.88 \pm .17, \mathrm{~S} 2=1.21 \pm .12$; Day 2 means in $\log \sec \pm S E, \mathrm{~S} 1=2.03 \pm .11, \mathrm{~S} 2=1.71 \pm .16]$.

Of particular interest was the comparison of suppression to second-order cues that had been paired with firstorder CSs that had different temporal relationships to the US in Phase 1 . This comparison is particularly meaningful in the present experiment because care had been taken to control for a variety of factors related to the associative value of the context in which first-order conditioning, second-order conditioning, and testing had occurred. Under the controlled conditions of the present experiment, the results suggest that SOC is superior when first-order conditioning occurs in a backward (US $\rightarrow$ CS) relative to forward (CS $\rightarrow U S$ ) manner. To our knowledge, this is the first such demonstration and also provides the first evidence of excitatory SOC that is based on backward first-order US $\rightarrow$ CS pairings (Barnet \& Miller, 1996, present a related SOC effect, as did Matzel et al., 1988 , who demonstrated excitatory SPC based on backward first-order US $\rightarrow$ CS training).

Suppression to the forward trained first-order cue, S1, was superior to that of the backward conditioned firstorder cue, S2. According to the associative transfer view outlined earlier, the associative character of the firstorder cues, defined by their response potentials, should have transferred to the second-order stimuli with which they were paired. On this view, second-order conditioning to $\mathrm{S} 3$ (conditioned on the basis of $\mathrm{S} 1$ ) should have been superior to second-order conditioning to S4 (conditioned on the basis of S2). Given that the opposite outcome was
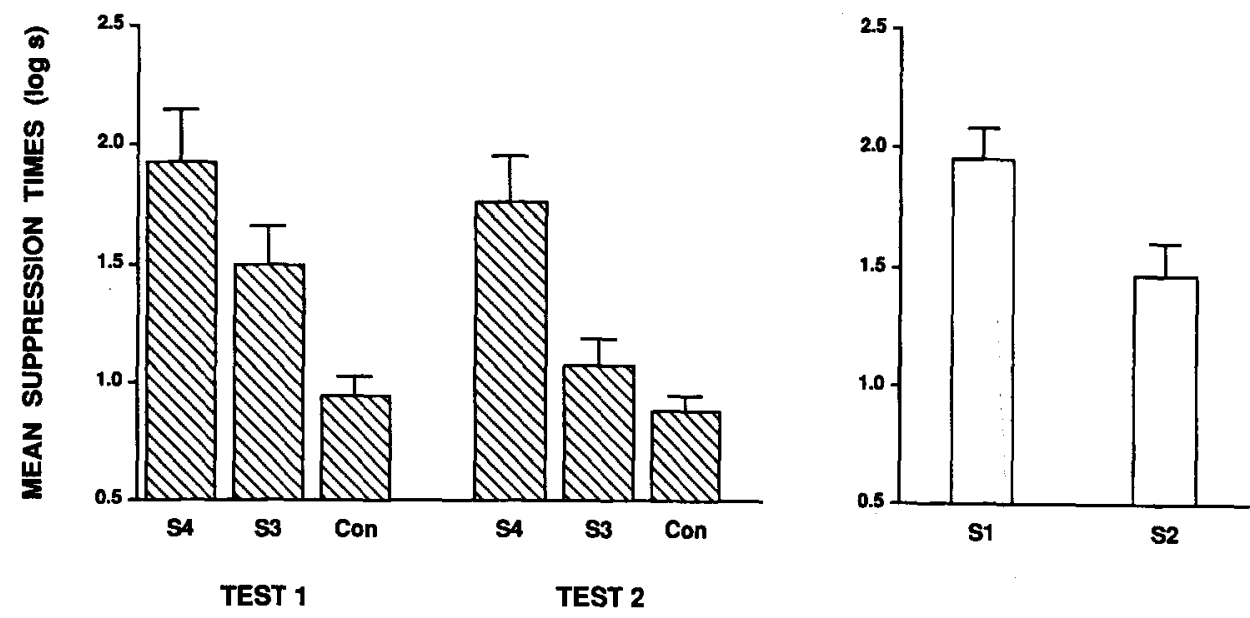

Figure 2. Experiment 1: mean suppression in the presence of second-order cues $S 3$ and $S 4$ and firstorder cues $S 1$ and $S 2$. S3 had been paired with the forward first-order cue S1, and S4 had been paired with the backward first-order cue $S 2$. Suppression to $S 3$ and suppression to $S 4$ for experimental subjects are shown separately. "Con" shows suppression to S3 and S4 (pooled) from control subjects. Error bars represent standard errors. 
observed, the associative transfer hypothesis would seem to be disfavored. A different possibility that remains viable is that presentation of either $\mathrm{S} 3$ or $\mathrm{S} 4$ during the test activated a forward expectancy of the US, but the temporal character of that expectancy differed, depending on which second-order cue was presented.

Some aspects of the Kehoe et al. (1981) experiment mentioned earlier, which was consistent with the associative transfer view, may also be understood by variation in the temporal character of US expectancy. In that experiment, the character of excitatory SOC tracked the associative character of the first-order CS, S1, which was manipulated by varying the S1-US interval. Under conditions in which Kehoe et al. observed decreases in excitatory SOC with increases in the $\mathrm{S} l \rightarrow$ US interval, the temporal encoding analysis might suggest that the effect of increasing the $\mathrm{S} 1 \rightarrow$ US interval, given the forward higher order (Phase 2) pairings that Kehoe et al. used, was to increase the expected delay to the US relative to test presentation of the higher order cue (with an according decrease in excitatory control by the higher order stimulus).

Variation in predictive value may also provide an understanding of the difference in behavioral control by stimuli forward or backward paired with a US (i.e., S1 and S2). According to the temporal coding hypothesis, differences in predictive value are important for behavioral expression of "excitatory" learning. Because this hypothesis assumes that temporal contiguity is sufficient for associative acquisition, $\mathrm{S} 1$ and $\mathrm{S} 2$ are both presumed to be well associated with the US. Indeed, these associations with the US are those that are presumed to have supported the acquisition of excitatory SOC to S3 and S4. The presence of associations with the US, however, does not ensure that a first-order $\mathrm{CS}$ will serve as a strong behavioral excitor, as a comparison of suppression to S2 and S1 in Figure 2 suggests. Suppression to $S 2$ may be inferior to that of S1 for reasons other than S2's being weakly associated with the US. According to the temporal coding hypothesis, differences in behavioral control by $\mathrm{S} 1$ and S2 were mediated by differences in the expression of temporal information encoded in the associations, not by differences in associative strength.

Two further interpretations of the present experiment, however, do not demand assumptions of temporal encoding. One alternative account emerges from models of associative learning which assume that the acquisition of conditioned inhibition to a cue will be facilitated when a neutral cue is nonreinforced in the presence of a strong excitor (e.g., Rescorla \& Wagner, 1972). During the secondorder conditioning phase of Experiment 1, the neutral S3 was nonreinforced in the presence of a strong excitor (the forward conditioned S1) and the neutral S4 was nonreinforced in the presence of a weak excitor (the backward conditioned S2 [S3 $\rightarrow \mathrm{S} 1, \mathrm{~S} 4 \rightarrow \mathrm{S} 2$, see Table 1]). In this analysis, conditions for the acquisition of inhibition are more favorable for S3 than for S4. Thus, behavioral control by $\mathrm{S} 4$ may have been superior not because $\mathrm{S} 4$ was more excitatory than $\mathrm{S} 3$, but rather because $\mathrm{S} 3$ was more inhibitory than $\mathrm{S} 4$.
A second alternative account is that $\mathrm{S} 3$ supported less second-order excitation than did S4 because S3 was less well learned about than $\mathrm{S} 4$. This account relies on the effect of presenting strong versus weak first-order excitors after the target second-order cues. The possibility exists that following S3 with the highly excitatory S1 during the second-order conditioning phase $(\mathrm{S} 3 \rightarrow \mathrm{S} 1)$ had the effect of attenuating postperceptual processing of S3. That is, the highly excitatory S1 may have distracted animals from processing the representation of $S 3$, rendering S3 less likely to enter into associations of any kind. Therefore, S3 should be less capable of supporting excitatory responding. Such distraction could be expected to be less for $\mathrm{S} 4$, because the stimulus that followed it during the second-order conditioning phase, the backward conditioned S2, was less excitatory $(\mathrm{S} 4 \rightarrow \mathrm{S} 2)$.

Both of these inhibition and distraction views demand that there be differences in the associative status of the first-order conditioned cues at the time that higher order conditioning takes place. That is, the first-order conditioned cues $\mathrm{S} 1$ and $\mathrm{S} 2$ must be differently excitatory at the time of the $\mathrm{S} 3 \rightarrow \mathrm{S} 1$ and $\mathrm{S} 4 \rightarrow \mathrm{S} 2$ pairings if they are to differentially influence the course of higher order conditioning to S3 and S4. In Experiment 2, we evaluated these views by reversing the phases of training relative to their order in Experiment 1.

\section{EXPERIMENT 2}

The primary goal of Experiment 2 was to determine whether the magnitude of SPC would differ depending on whether the first-order stimulus had been forward or backward paired with the US. In Experiment 2, SPC training with $\mathrm{S} 3$ and $\mathrm{S} 4(\mathrm{~S} 3 \rightarrow \mathrm{S} 1 / \mathrm{S} 4 \rightarrow \mathrm{S} 2$ [now Phase 1]) preceded reinforced first-order conditioning with $\mathrm{S} 1$ and $\mathrm{S} 2$ (S1 $\rightarrow$ US/US $\rightarrow$ S2 [now Phase 2]). We have already suggested that an explanation of the SOC data from Experiment 1 that is based on simple associative transfer does not seem viable. However, if the pattern of control by $\mathrm{S} 3$ and $\mathrm{S} 4$ in Experiment 1 was caused by differences in the excitatory value of the first-order cues at the time of higher order conditioning, in a manner suggested by the inhibition and distraction views, that pattern should be eliminated in the present SPC design. This is so, because in the SPC design all cues (S1, S2, S3, and S4) are equally neutral at the time of Phase 1 preconditioning (i.e., at the time of $\mathrm{S} 3 \rightarrow \mathrm{S} 1$ and $\mathrm{S} 4 \rightarrow \mathrm{S} 2$ pairings). In contrast, if differences in suppression to $\mathrm{S} 3$ and $\mathrm{S} 4$ were mediated by differences in the expected temporal location of the US suggested by the integrated temporal maps at the bottom of Figure 1, predictions are essentially unchanged for Experiments 1 and 2.

\section{Method}

\section{Subjects and Apparatus}

The subjects were 30 male and 30 female naive Sprague-Dawleydescended rats. Body weight ranges were $310-465 \mathrm{~g}$ for males and 260-320 g for females. Animal housing and maintenance, the apparatus, and stimuli were all the same as in Experiment 1. 


\section{Procedure}

The design of Experiment 2 was identical to that of Experiment 1, except for the order of training phases. In the present SPC design, nonreinforced training (e.g., S3 $\rightarrow \mathrm{S} 1 / \mathrm{S} 4 \rightarrow \mathrm{S} 2$ ) now occurred during Phase 1 , and reinforced first-order conditioning $(\mathrm{S} 1 \rightarrow \mathrm{US} / \mathrm{US} \rightarrow \mathrm{S} 2)$ now occurred during Phase 2 . The only aspect of the Experiment 2 that otherwise differed as a result of this change was that Group First-Order received the nonreinforced (SPC) training before testing with the first-order cues, S1 and S2 (because SPC training now preceded first-order conditioning, which naturally had to precede the tests with $\mathrm{S} 1$ and $\mathrm{S} 2$ ).

During Phase 1 , the animals were exposed to SPC training in Context Test, followed by Phase 2 first-order conditioning in Context Train. Testing occurred in Context Test as in Experiment 1.

\section{Results and Discussion}

The results of the present experiment using SPC replicate and extend the results of Experiment 1, which used an SOC design. In the present experiment, SPC was superior when the first-order cue had been backward paired with the US (US $\rightarrow$ S2) relative to when the first-order cue had been forward paired with the US (S1 $\rightarrow$ US).

Results from the tests with the sensory preconditioned cues (S3 and S4) and the first-order cues (S1 and S2) are summarized in Figure 3. Initial analyses of suppression to the sensory preconditioned cues revealed an interaction with order of testing (the general pattern of suppression to S3 and S4, however, did not differ depending on order of test). Consequently, data from Test 1 and Test 2 were analyzed and presented separately. The primary implication from Figure 3 is that S4 supported more conditioned suppression than did S3, a pattern of suppression that was preserved on both days of testing. As in Experiment 1 with SOC, excitatory conditioning to a higher order cue in Experiment 2 with SPC was superior when that conditioning was based on first-order backward conditioning (US $\rightarrow \mathrm{S} 2$ ) relative to when that conditioning was based on first-order forward conditioning ( $\mathrm{S} 1 \rightarrow \mathrm{US}$ ).
Two one-way ANCOVAs (one for each day of testing) were conducted with pre-CS scores as the covariate, and planned comparisons were then conducted with the error term from each analysis. The Test 1 analysis revealed an overall effect of test stimulus $[F(2,32)=27.06, p<.001]$. Subsequent comparisons indicated that suppression to $\mathrm{S} 3$ and S4 each differed from that of the control condition $[F \mathrm{~s}(1,32)>9.50, p \mathrm{~s}<.01]$. Of central interest, suppression to $S 4$ was superior to that to $S 3[F(1,32)=18.14$, $p<.001]$. The Test 2 analysis also revealed an effect of test stimulus $[F(2,32)=28.99, p<.001]$. Planned comparisons indicated that suppression to $\mathrm{S} 4$ differed from that in the control condition $[F(1,32)=61.50, p<.001]$, as did suppression to $S 3[F(2,32)=6.33, p<.025]$. As can be seen in Figure 3, suppression to $\mathrm{S} 4$ was again superior to that to $\mathrm{S} 3[F(1,32)=28.35, p<.001]$.

Data from the tests with the first-order cues were as expected; excitatory conditioning was better after forward first-order conditioning than after backward first-order conditioning. These data are summarized in the right portion of Figure 3. Suppression to the forward conditioned S1 was superior to that to the backward conditioned S2 on each test, an outcome that was marginally significant in an overall ANCOVA with pre-CS scores as the covariate $(p=.06$, Day 1 means in $\log \mathrm{sec} \pm S E, \mathrm{~S} 1=1.63 \pm .15$, $\mathrm{S} 2=1.37 \pm .16$; Day 2 means in $\log \mathrm{sec} \pm S E, \mathrm{~S} 1=1.51$ $\pm .13, \mathrm{~S} 2=1.32 \pm .14)$.

The conditioned inhibition and distraction views presented in the Introduction above are not supported by the outcomes of the present experiment. In those views, the pattern of behavioral control by S3 and S4 seen in Experiment 1 was mediated by the acquisition of inhibition to $\mathrm{S} 3$ or by a failure to learn about $\mathrm{S} 3$ because of distraction or interference from the first-order $S 1$ during the $\mathrm{S} 3 \rightarrow \mathrm{S} 1$ pairings. Both of these views attributed differences in the pattern of behavioral control by S3 and $\mathrm{S} 4$ to differences in the excitatory value of the first-order
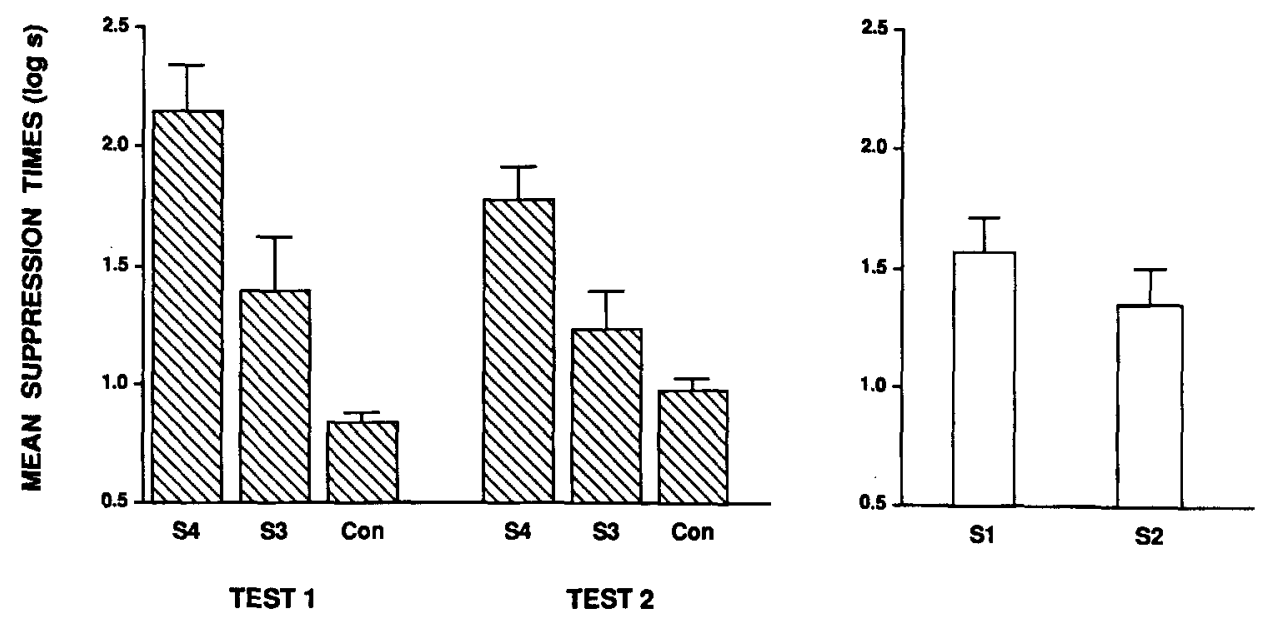

Figure 3. Experiment 2: mean suppression in the presence of sensory preconditioned cues $\mathbf{S 3}$ and $\mathbf{S 4}$ and first-order cues $\$ 1$ and $S 2 . S 3$ had been paired with the forward first-order cue S1, and S4 had been paired with the backward first-order cue $\mathbf{S 2}$. Suppression to $S 3$ and suppression to $S 4$ for experimental subjects are shown separately. "Con" shows suppression to S3 and S4 (pooled) from control subjects. Error bars represent standard errors. 
cues at the time that second-order training took place (i.e., at the time of the $\mathrm{S} 3 \rightarrow \mathrm{S} 1 / \mathrm{S} 4 \rightarrow \mathrm{S} 2$ phase). A benefit of using the SPC design in Experiment 2 was that it allowed training with the S3 and S4 cues to occur at a time when differences in the associative value of the firstorder stimuli was not likely-namely, before any reinforced training with $\mathrm{S} 1$ and S2. Despite the presumed absence of differences in the associative value of the firstorder cues at the time of higher order training with S3 and S4, the pattern of suppression to S3 and S4 seen in Experiment 1 was replicated in the present experiment. Therefore, the inhibition and distraction views are not supported. An alternative presented earlier is that differences in suppression to $\mathrm{S} 3$ and $\mathrm{S} 4$ were controlled by differences in the expected temporal location of the US at the time of the test. Data from the present experiment suggest that the conditioning of these temporal expectancies may occur in both SPC and SOC.

\section{GENERAL DISCUSSION}

The experiments revealed that SOC (Experiment 1) and SPC (Experiment 2) were superior when that conditioning was based on backward (US $\rightarrow$ CS ) relative to forward (CS $\rightarrow$ US ) first-order training. These outcomes may be understood by the assumption that temporal information such as order between paired CSs and USs was encoded, preserved, and integrated with memory for the higher order (i.e., second-order and sensory preconditioned) cues, S3 and S4. We hypothesized that a consequence of that integration was the generation of different expectancies for the temporal location of the US during the tests with the higher order cues. Consistent with other similarly motivated work (Cole et al., 1995), these data suggest that variation in the temporal relationship between a first-order CS and US is an important determinant of both SOC and SPC. A benefit of the present experimental design was that that variation occurred without confounding the associative value of the context across comparison conditions at the time of reinforced training, higher order conditioning, or at the time of testing (cf. Matzel et al., 1988).

Notably, these results offer the first demonstration of excitatory SOC that is based on first-order backward $\mathrm{US} \rightarrow \mathrm{CS}$ training (Barnet \& Miller, 1996, present a related finding). This outcome itself is important, because it suggests that the relative weakness of first-order backward excitatory conditioning observed here and elsewhere (Heth \& Rescorla, 1973; Smith, Coleman, \& Gormezano, 1969) does not result entirely from a weakness in associative learning between a backward CS and US (Mackintosh, 1974; Pavlov, 1927). The outcome of the test with the first-order conditioned cues, S1 and S2, is particularly instructive in this regard. Excitatory control by the backward conditioned CS was inferior to that of the forward conditioned CS (compare the S1 and S2 means in Figure 2). One interpretation of that behavioral difference might be that forward conditioning with $\mathrm{S} I$ produced a stronger association to the US than did back- ward conditioning with $\mathrm{S} 2$. In this view, behavioral control by $\mathrm{S} 1$ was superior because associations to the US were stronger for the forward conditioned S1. However, the results of the SOC test do not support this view. The observation of robust SOC to S4 suggests that the backward conditioned $\mathrm{S} 2$ was well associated with the US. If the associative value of S2 was weak relative to that of S1, suppression to $\mathrm{S} 4$ (conditioned on the basis of $\mathrm{S} 2$ ) should have been weak relative to that of $S 3$ (conditioned on the basis of S1). These findings suggest that the inferiority of backward relative to forward first-order conditioning is not caused by an inferiority of associative learning after backward US $\rightarrow$ CS training.

On this issue, Gordon (1985) has considered one possible explanation for findings in backward conditioning based on cuing (i.e., "reminder") experiments with rats. Gordon considered one possibility in which manipulating the order of a CS and US (e.g., backward pairings), while not influencing the formation of associations, might influence the ease of retrieval of a CS-US association. In this view, the relative weakness of backward relative to forward conditioning might reflect difficulty of retrieving the focal CS-US association after backward training. Here we suggest an alternative explanation for the difference in excitatory control by backward and forward conditioned CSs that is consistent with outcomes of the present experiments. Specifically, we have suggested that those behavioral differences may reflect the expression of different temporal information during testing that was encoded in the associations at the time of reinforced training. The possibility raised by the present data and analysis, therefore, is that order may not influence the ease of retrieval but instead influences what gets retrieved.

What gets retrieved in the present analysis is order information concerning the CS and US, which may then become integrated with cues present at the time of that retrieval (i.e., S3 and S4). We hypothesized that one possible consequence of such integration in the present experiments was the generation of different expectancies concerning the temporal location of the US that became activated upon presentation of the higher order cues, S3 and S4 (see Figure 1).

In Experiment 1, SOC was superior when based on backward relative to forward first-order training. That outcome argued against a simple associative transfer view in which the associative character of the first-order stimuli, defined by their response potentials, simply transfers to the higher order cues. Had that been the case, suppression to S3 (conditioned on the basis of the "strong" forward excitor, S1) should have been superior to that of S4 (conditioned on the basis of the "weak" backward excitor, S2). Because S1 was a stronger excitor than S2 in Experiment 1, the possibility was raised that the strongly excitatory $\mathrm{S} 1$ could either distract animals from processing S3, or facilitate the acquisition of inhibition to S3 (cf. Rescorla \& Wagner, 1972) during the second-order conditioning phase (i.e., during the $\mathrm{S} 3 \rightarrow \mathrm{S} 1 / \mathrm{S} 4 \rightarrow \mathrm{S} 2$ pairings). If $\mathrm{S} 3$ was subject to more distraction than $\mathrm{S} 4$, or if $\mathrm{S} 3$ acquired more inhibition than $\mathrm{S} 4$, less excitatory con- 
ditioning to $\mathrm{S} 3$ than $\mathrm{S} 4$ would be anticipated. Given that this was precisely the outcome of Experiment 1, Experiment 2 was conducted under conditions in which animals were exposed to the $\mathrm{S} 3 \rightarrow \mathrm{S} 1 / \mathrm{S} 4 \rightarrow \mathrm{S} 2$ pairings prior to any reinforced training with the first-order cues, S1 and S2. In this SPC design of Experiment 2, S1 and S2 would not be expected to exert any differential impact over the processing of $\mathrm{S} 3$ and $\mathrm{S} 4$ at the time of the $\mathrm{S} 3 \rightarrow \mathrm{S} 1$ / $\mathrm{S} 4 \rightarrow \mathrm{S} 2$ pairings, because at the time of those pairings, $\mathrm{S} 1$ and S2 had not yet been differentially reinforced. However, Experiment 2 replicated the central effects observed in Experiment 1. Suppression to S4 (conditioned on the basis of $\mathrm{S} 1$ ) was superior to that to $\mathrm{S} 3$ (conditioned on the basis of S2). Thus, the outcomes from Experiment 2 tend to disfavor the distraction and inhibition interpretations of the second-order conditioning effects observed in Experiment 1.

It would be prudent, however, to view these effects on SOC and SPC with a degree of caution. In Experiment 2, forward first-order conditioning was only marginally superior to backward first-order conditioning in supporting suppression to the test CSs (see Figure 3 ). In fact, the difference between suppression to the forward conditioned $\mathrm{S} 1$ and the backward conditioned $\mathrm{S} 2$ in that experiment was only marginally significant. One potential problem with that outcome is this: If encoded temporal (i.e., order) information was responsible for the observed discriminated suppression to S3 and S4, why was that encoded temporal information not sufficient to support robust discriminated suppression to $S 1$ and $S 2$ ?

One possibility is that training with $\mathrm{S} 1$ and $\mathrm{S} 2$ was insufficient to support discriminated suppression to $\mathrm{S} 1$ and $S 2$, but with further reinforced training suppression to $S 1$ and $\mathrm{S} 2$ would have further diverged. For example, to the extent that extended backward conditioning supports the recruitment of conditioned inhibition (Heth, 1976), extended training in Experiment 2 (and Experiment 1) might have supported the acquisition of inhibition to S2, lowering S2's excitatory response potential and thereby increasing the difference in suppression between $\mathrm{S} 1$ and $\mathrm{S} 2$. Such a set of circumstances might allow the encoding of temporal (order) information with the limited reinforced training given here without demanding that suppression to the backward CS be dramatically lower than suppression to the forward first-order CS. Two further points on this issue should be noted. First, in all tests with $\mathrm{S} 1$ and $\mathrm{S} 2$, the tendency was for the forward conditioned S1 to support more suppression than did the backward conditioned S2. Second, even a complete absence of behavioral differences in suppression to S1 and S2 would not centrally damage the temporal encoding interpretation of the SOC and SPC data. That interpretation would be damaged if $\mathrm{S} 2$ tended to support more suppression than S1. In no case did that occur.

An interesting proposal that considers dynamic response eliciting characteristics of the first-order CSs, however, may offer a plausible alternative to the temporal encoding interpretation. This view capitalizes on the possibility that different components of S1 and S2 were differentially excitatory. Given that the US was most proximal to $\mathrm{S} 1$ termination (S1 $\rightarrow$ US) but most proximal to $\mathrm{S} 2$ onset (US $\rightarrow \mathrm{S} 2$ ), it is possible that the termination of S1 was more excitatory than its onset, and, conversely, that the onset of S2 was more excitatory than its termination. The logic of this proposal is clearest for Experiment 1, which used the SOC procedure. After differential conditioning of CS onsets and terminations in Phase 1 , second-order conditioning (S3 $\rightarrow \mathrm{S} 1 / \mathrm{S} 4 \rightarrow \mathrm{S} 2$ ) may have had the consequence of conditioning S3 to the weakly excitatory S1 onset, but conditioning S4 to the strongly excitatory S2 onset. Thus, S3 would appear to be more weakly conditioned than $\mathrm{S} 4$, as was the case in these experiments.

The preceding position requires a bit more complexity if one is to deal with the outcome of Experiment 2, which used a SPC design. This is so, because differential conditioning of onsets and terminations would not occur until after the higher order conditioning phase. Here the view requires that, during the second, reinforced phase $(\mathrm{S} 1 \rightarrow \mathrm{US} / \mathrm{US} \rightarrow \mathrm{S} 2), \mathrm{S} 1$ and S2 retroactively activated representations of $S 3$ and $S 4$, respectively, and that the (weak) responses elicited by $\mathrm{S} 1$ onset became conditioned to the activated S3 representation, whereas the (strong) responses elicited by $\mathrm{S} 2$ onset became conditioned to the activated S4 representation. To the extent that this occurred, S3 might come to elicit weaker suppression responses than would S4. An alternate possibility for this account of SPC is that differential suppression to $S 3$ and $\mathrm{S} 4$ occurred as a result, for example, of the test presentation of S3 activating the associated S1 representation (see note 1), which then elicited the weak S1 onset response, giving the appearance of weak sensory preconditioning to S3. Following a similar logic for S4, S4 during the test could have activated its associated representation of S2 (see note 1), which then elicited the strong S2 onset response and the consequent appearance of stronger sensory preconditioning to $\mathrm{S} 4$. Although this view of the higher order cues' becoming conditioned to responses elicited by CS onsets and terminations loses a degree of elegance in accounting for the SPC data of Experiment 2, it can in principle explain outcomes of both experiments presented here.

Evaluation of the preceding possibility requires a measure of suppression that is temporally distributed across the duration of test stimuli. No such measure was available in the present work. A more detailed consideration of the Cole et al. (1995) report mentioned in the general introduction, however, may be instructive. Cole et al. (Experiment 1) exposed rats to forward first-order conditioning with either a 0 -sec delay between $\mathrm{S} 1$ and the US $(\mathrm{S} 1 \rightarrow \mathrm{US})$, or a 5 -sec unfilled gap between $\mathrm{S} 1$ and the US ( $\mathrm{S} 1 \rightarrow \mathrm{US}$ ). This first-order conditioning experience was followed by identical "backward" second-order conditioning for all animals, in which $\mathrm{S} 1$ immediately preceded the second-order cue $\mathrm{S} 3$ ( $\mathrm{S} 1 \rightarrow \mathrm{S} 3$ [0-sec delay between S1 and S3; S1 was $10 \mathrm{sec}$ and S3 was $5 \mathrm{sec}$ in 
duration]). Data from tests with the first-order cue, S1, revealed moderate suppression to $S 1$ in animals previously conditioned with a 0-sec gap (standard delay conditioning), and weaker low suppression to $\mathrm{S} 1$ in animals conditioned with a 5-sec gap (a trace conditioning deficit). The surprising outcomes of that experiment were found in suppression to the second-order cue, S3. Second-order conditioning to $\mathrm{S} 3$ was superior when that conditioning was based on the $S 1$ previously conditioned with the 5-sec gap, relative to when that conditioning that was based on the S1 previously conditioned with no gap. As in the present experiments, the first-order CS that itself supported less first-order conditioning was in fact precisely the CS that promoted superior second-order conditioning. We interpreted those findings in a manner consistent with the temporal encoding position developed here, in which differences in suppression to the second-order cue were presumed to be controlled by differences in the expected temporal location of the US (see Cole et al. for elaboration). The potential relevance of these findings is as follows.

First, one might expect that in Cole et al. (1995) S1 termination would have been more excitatory than $\mathrm{S} 1$ onset at both $\mathrm{S} 1 \rightarrow$ US intervals because at both intervals S1 termination was most proximal to the US. Thus, the $\mathrm{S} 1$ onsets and terminations were not likely differentially excitatory at different levels of CS $\rightarrow$ US interval, as might be argued with respect to the present experiments. Second, in both the 0 -sec delay and the 5-sec gap conditions, responses produced by $\mathrm{S} 1$ termination should have become conditioned to the second-order cue S3, because in both cases presentation of S3 was temporally and equally contiguous with $\mathrm{S} 1$ termination. Third, S1 termination in the 0 -sec delay condition should have been more excitatory than S1 termination in the 5-sec gap condition, because the US was more proximal to S1 termination in the 0 -sec delay condition. Following the logic of the response-producing characteristics of the CS onset and termination view that may explain aspects of data from the present experiments, in Cole et al., S3 should have become conditioned to the highly excitatory S1 termination in the 0 -sec delay condition but should have become conditioned to the weakly excitatory S1 termination in the 5-sec gap condition. Therefore, S3 should have supported more second-order conditioning when $\mathrm{S} 1$ was conditioned with the 0 -sec delay than when S1 was conditioned with a 5-sec gap. In evidence for Cole et al., exactly the opposite outcome was observed. Therefore, an account in terms of dynamic response-eliciting characteristics of the first-order CSs may explain data from the experiments presented here, but it encounters difficulty in dealing with data from Cole et al., which, like those presented here, may be understood by assuming that temporal information across separate phases of training became integrated in associative memory.

The preceding onset/termination view remains appealing, in part because it offers a specified mechanism of conditioning that occurs during the higher order condi- tioning stage and one that is parsimonious and consistent with conventional learning theory (at least for SOC, through the establishment of S-R bonds between CS onsets/terminations and the conditioned response). It could be argued, however, that it is neither more mechanistic nor elegant than the temporal encoding alternative, as it might seem at first glance (especially in its somewhat more complex account of SPC). Nevertheless, parsimony is sometimes in the eye of the beholder, and the onset/ termination view remains a viable alternative for the present experiments, if not for those of Cole et al. (1995).

Although not by intention, the results of the present work may also have implications for the associative structure that underlies second-order Pavlovian fear conditioning. As mentioned in the general introduction, one question concerning SOC has been what associative structure underlies responding to a second-order cue in Pavlovian fear conditioning. A variety of different possibilities have been identified, and we will not detail them here (see Barnet et al., 1991; Rizley \& Rescorla, 1972, for detailed descriptions). Here we will only point out one particular structure that has been implicated, at least from SOC experiments involving adult rats and aversive USs (Rescorla, 1973, 1974; Rizley \& Rescorla, 1972). The favored structure underlying SOC, again from experiments with adult rats and aversive USs, has been characterized as an $\mathrm{S}-\mathrm{R}$ bond between the second-order cue and the conditioned-response (CR; Rescorla, 1973, 1974; Rizley \& Rescorla, 1972; see Rescorla, 1982, for an exception). In standard SOC ( $\mathrm{S} 1 \rightarrow$ US in Phase 1 , followed by $\mathrm{S} 3 \rightarrow \mathrm{S} 1$ in Phase 2), the first-order $\mathrm{S} 1$ and the US are forward paired prior to the SOC phase with S3. In this procedure, the first-order CS comes to elicit a strong CR by virtue of forward first-order conditioning. In the $S-R$ account, when the first-order and second-order cues are paired during the SOC phase (S3 $\rightarrow \mathrm{S} 1)$, S1 elicits a strong response by virtue of the forward $\mathrm{S} 1 \rightarrow$ US preconditioning. It is the response elicited by $\mathrm{S} 1$ during the $\mathrm{S} 3 \rightarrow \mathrm{S} 1$ pairings that is presumed to become associated with the second-order cue S3, because $S 3$ and the response elicited by $\mathrm{S} 1$ occur in close temporal proximity. According to Rescorla (1973; cited in Rescorla, 1976), "second-order conditioning depends upon the magnitude of the response evoked by the first-order stimulus" (p. 168). Thus, the S-R account posits an S3 $\rightarrow$ CR associative structure, the control of which is determined by the response to the firstorder cue (note that what we have called the "associative transfer" view and the S-R view of SOC make similar predictions). Data from the present experiment are not in accord with this view. In the present experiment, the backward conditioned S2 elicited a weaker CR than did the forward conditioned S1 (see Figure 2). If it is the response elicited by the first-order cue that becomes associated with the second-order stimulus, suppression to the second-order S3 (conditioned on the basis of S1 which elicited a strong $C R$ ) should have been superior to suppression to the second-order S4 (conditioned on the basis of S2 which elicited a weak CR). In fact, the oppo- 
site outcome occurred. Thus, the present data suggest that acceptance of the $S-R$ viewpoint for SOC with adult rats and aversive USs is premature and possibly incorrect (cf. Rashotte, 1981).

Finally, the results may also provide one speculation concerning the dynamics of temporal information processing. In both SOC and SPC, it may be presumed that at some time during training, something is learned about the temporal order of the higher order cue and the firstorder stimulus (i.e., that $\mathrm{S} 3$ predicts $\mathrm{S} 1[\mathrm{~S} 3 \rightarrow \mathrm{S} 1]$ or that $\mathrm{S} 4$ predicts $\mathrm{S} 2$ [S4 $\rightarrow \mathrm{S} 2]$ ). That some order learning of this kind occurs may be true for both SOC and SPC, but in SPC that learning occurs when all the cues are neutral. In SOC, that same learning occurs at a time when the firstorder stimuli have already been transformed into conditioned excitors. To the extent that similar mechanisms are responsible for the outcomes of Experiment 1 (SOC) and Experiment 2 (SPC), these considerations raise the possibility, at least for the encoding of order information, that so-called neutral cues and CSs either are represented similarly in the associative memory system or suggest a similarity in the nature of the processes that operate on those representations.

A final caveat of the present experiments offers somewhat of a procedural warning: the conditions that are optimal for excitatory first-order conditioning, such as those that produce short-delay forward conditioning, are not necessarily those that should be adopted into a design in which the goal is to produce optimal SOC or SPC. In determining which first-order parameters are best suited for optimal higher order conditioning, the present work might encourage consideration of how memory in higher order learning is organized, not simply how well the first-order stimuli control behavior.

\section{REFERENCES}

Barnet, R. C., ARnold, H. M., \& Miller, R. R. (1991). Simultaneous conditioning demonstrated in second-order conditioning: Evidence for similar associative structure in forward and simultaneous conditioning. Learning \& Motivation, 22, 253-268.

BARNet, R. C., \& Miller, R. R. (1996). Second-order excitation mediated by a backward conditioned inhibitor. Journal of Experimental Psychology: Animal Behavior Processes, 22, 279-296.

BROGDEN, W. J. (1939). Sensory pre-conditioning. Journal of Experimental Psychology, 25, 323-332.

Brown, C. P., \& KING, M. G. (1969). Backward sensory preconditioning: The ineffectiveness of the procedure under optimal conditions. Australian Journal of Psychology, 21, 55-58.

Cole, R. P., Barnet, R. C., \& Miller, R. R. (1995). Temporal encoding in trace conditioning. Animal Learning \& Behavior, 23, 144-153.

COPPOCK, W. J. (1958). Pre-extinction in sensory preconditioning. Journal of Experimental Psychology, 55, 213-219.

DESMOND, J. E., \& MOORE, J. W. (1988). Adaptive timing in neural networks: The conditioned response. Biological Cybernetics, 58, 405-415.

ElLISON, G. D. (1964). Differential salivary conditioning to traces. Journal of Comparative \& Physiological Psychology, 57, 373-380.

GoRDON, W. C. (1985). The effect of cuing after backward conditioning trials. Learning \& Motivation, 16, 444-463.

Grau, J. W., \& Rescorla, R. A. (1984). Role of context in autoshaping. Journal of Experimental Psychology: Animal Behavior Processes, 10, 324-332.
Heth, C. D. (1976). Simultaneous and backward fear conditioning as a function of the number of CS-US pairings. Journal of Experimental Psychology: Animal Behavior Processes, 2, 117-129.

Heth, C. D., \& Rescorl.A, R. A. (1973). Simultaneous and backward fear conditioning in the rat. Journal of Comparative \& Physiological Psychology, 82, 434-443.

HoNIG, W. K. (1981). Working memory and the temporal map. In N. E. Spear \& R. R. Miller (Eds.), Information processing in animals: Memory mechanisms (pp. 167-197). Hillsdale, NJ: Erlbaum.

KehoE, E. J., Feyer, A.-M., \& Moses, J. L. (1981). Second-order conditioning of the rabbit's nictitating membrane response as a function of the CS2-CS1 and CS1-US intervals. Animal Learning \& Behavior, 9, 304-315.

Kimble, G. A. (1947). Conditioning as a function of the time between conditioned and unconditioned stimuli. Journal of Experimental $P$ sychology, 37, 1-15.

Mackintosh, N. J. (1974). The psychology of animal learning. New York: Academic Press.

MARLIN, N. A. (1983). Second-order conditioning using a contextual stimulus as $\mathrm{S}_{1}$. Animal Learning \& Behavior, 11, 290-294.

Matzel, L. D., Held, F. P., \& Miller, R. R. (1988). Information and the expression of simultaneous and backward associations: Implications for contiguity theory. Learning \& Motivation, 19, 317-344.

Medin, D. L., \& DeweY, G. I. (1986). Memory theories: Past, present, and projected. In D. F. Kendrick, M. E. Rilling, \& M. R. Denny (Eds.), Theories of animal memory (pp. 173-196). Hillsdale, NJ: Erlbaum.

MiLLER, R. R., \& BARNET, R. C. (1993). The role of time in elementary associations. Current Directions in Psychological Science, 2, 106-111.

Miller, R. R., Grahame, N. J., \& Hallam, S. C. (1990). Summation of responding to CSs and an excitatory test context. Animal Learning \& Behavior, 18, 29-34.

Moscovitch, A., \& LoLordo, V. M. (1968). Role of safety in the Pavlovian backward fear conditioning procedure. Journal of Comparative \& Physiological Psychology, 66, 673-678.

Mowrer, R. R., KRUG, D. E., \& KLEIN, S. B. (1988). Backward secondorder conditioning in flavor aversion learning. Psychological Record, 38, 259-269.

Pavlov, I. P. (1927). Conditioned reflexes (G. V. Anrep, Trans.). London: Oxford University Press.

RASHOTTE, M. E. (1981). Second-order autoshaping: Contributions to the research and theory of Pavlovian reinforcement by conditioned stimuli. In C. M. Locurto, H. S. Terrace, \& J. Gibbon (Eds.), Autoshaping and conditioning theory (pp. 139-180). New York: Academic Press.

RESCORLA, R. A. (1973). Effect of US habituation following conditioning. Journal of Comparative \& Physiological Psychology, 82, 137-143.

RESCORLA, R. A. (1974). Effect of inflation of the unconditioned stimulus value following conditioning. Journal of Comparative \& Physiological Psychology, 86, 101-106.

Rescorla, R. A. (1976). Second-order conditioning of Pavlovian conditioned inhibition. Learning \& Motivation, 7, 161-172.

RESCORLA, R. A. (1982). Simultaneous second-order conditioning produces S-S learning in conditioned suppression. Journal of Experimental Psychology: Animal Behavior Processes, 8, 23-32.

REsCoRla, R. A. (1984). Signaling intertrial shocks attenuates their negative effect on conditioned suppression. Bulletin of the Psychonomic Society, 22, 225-228.

Rescorla, R. A., \& Wagner, A. R. (1972). A theory of Pavlovian conditioning: Variations in the effectiveness of reinforcement and nonreinforcement. In A. H. Black \& W. K. Prokasy (Eds.), Classical conditioning II: Current research and theory (pp. 64-99). New York: Appleton-Century-Crofts.

Rizley, R. C., \& Rescorla, R. A. (1972). Associations in second-order conditioning and sensory preconditioning. Journal of Comparative \& Physiological Psychology, 81, 1-11.

SChreurs, B. G., \& WestBrooK, R. F. (1982). The effect of changes in the CS-US interval during compound conditioning upon an otherwise blocked element. Quarterly Journal of Experimental Psychology, 34B, 19-30.

Siegel, S., \& Domjan, M. (1971). Backward conditioning as an inhibitory procedure. Learning \& Motivation, 2, 1-11. 
SILVER, C. A., \& MEYER, D. R. (1954). Temporal factors in sensory preconditioning. Journal of Comparative \& Physiological Psychology, 47, 57-59.

Smith, M. C., Coleman, S. R., \& Gormezano, I. (1969). Journal of Comparative \& Physiological Psychology, 69, 226-231.

Tait, R. W., Marquis, H. A., Williams, R., WeINSTEIN, L., \& Suboski, M. D. (1969). Extinction of sensory preconditioning using CER training. Journal of Comparative \& Physiological Psychology, 69, $170-172$.

\section{NOTE}

1. Two points may be noted in this presentation. First, the bottom portions of Figure 1 imply that $S 1$ and S2 are part of the memory repre- sentation for S3 and S4, respectively. This is not necessarily the case. The first-order cues S1 and S2 are clearly important in the establishment of SOC, but once SOC is established, memory for the first-order $\mathrm{S} 1$ or S2 does not necessarily continue to be critical in control by the higher order cues. Relevant discussions on this issue may be found in Barnet et al. (1991) and Rizley \& Rescorla (1972). Second, it would be premature to assume highly accurate encoding of duration for the expected temporal location of the US in this analysis. This is an issue of the extent of accuracy. We are currently exploring this and other issues related to temporal resolution.

(Manuscript received November 29, 1995; revision accepted for publication August 8, 1996.) 